\title{
Article \\ Post-COVID-19 Scenarios of Global Airline Traffic until 2040 That Reflect Airport Capacity Constraints and Mitigation Strategies
}

\author{
Marc Christopher Gelhausen *, Peter Berster and Dieter Wilken
}

Citation: Gelhausen, M.C.;

Berster, P.; Wilken, D. Post-COVID-19

Scenarios of Global Airline Traffic until 2040 That Reflect Airport Capacity Constraints and Mitigation Strategies. Aerospace 2021, 8, 300. https://doi.org/10.3390/ aerospace 8100300

Academic Editor: Michael Schultz

Received: 16 June 2021

Accepted: 11 October 2021

Published: 14 October 2021

Publisher's Note: MDPI stays neutral with regard to jurisdictional claims in published maps and institutional affiliations.

Copyright: (C) 2021 by the authors. Licensee MDPI, Basel, Switzerland. This article is an open access article distributed under the terms and conditions of the Creative Commons Attribution (CC BY) license (https:// creativecommons.org/licenses/by/ $4.0 /)$.

\author{
Institute for Air Transport and Airport Research, German Aerospace Center (DLR), 52134 Cologne, Germany; \\ peter.berster@dlr.de (P.B.); dieter.wilken@dlr.de (D.W.) \\ * Correspondence: marc.gelhausen@dlr.de; Tel.: +49-220-3601-2463
}

\begin{abstract}
Although there has been an unprecedented decline in traffic volume due to the COVID-19 crisis, robust growth in global demand for air transport services in the past means that air traffic is expected to recover in the long term. While capacity constraints are currently not a major topic at airports due to the extremely low levels of traffic, there is growing evidence to suggest that important nodes of the worldwide airport network will struggle to deal with capacity constraints after the recovery. The objectives of this research were therefore as follows: to elaborate long-term global passenger and flight volume scenarios in a post-COVID-19 world; to conduct an empirical and model-based analysis of the impact of limited airport capacity on the future development of air traffic in these scenarios; and to derive general strategies for mitigating capacity constraints at certain international airports. Thus, the main aim of this paper is to present a model-based scenario analysis of the long-term impact of the COVID-19 crisis on the capacity situation for airports. Our results indicate that once the pandemic is over, the capacity crunch will remain on the airports' agenda for some time.
\end{abstract}

Keywords: airport capacity constraints; air transport forecast; aircraft size; COVID-19; forecast model; mitigation measures; runway capacity

\section{Introduction}

Global air traffic is heavily concentrated on a relatively small number of important airports, the majority of which are either facing capacity problems or will face such problems in the near future. Although the COVID-19 crisis has released the pressure on airport capacity, global air traffic is expected to continue to grow in the long term, albeit at a pace that differs greatly between Asia and the Middle East on the one hand, and Europe and North America on the other. Whereas in Asia demand only began to grow during the last few decades and is now rapidly increasing, demand in North America is more mature as there is already a high propensity to fly and the growth in demand is relatively low compared to other markets. Demand in Europe, however, will continue to grow, albeit at a reduced rate.

These differing expectations with respect to air traffic growth imply that future capacity problems will be less severe at major airports in North America than at Asian airports such as Delhi, Jakarta, Mumbai, and others. Due to further long-term growth in demand and political difficulties with populations living in the vicinity of airports who oppose the development of new airport capacity, the problem of overcoming airport constraints is likely to be aggravated in the future, primarily in Europe. The research question addressed in this paper is as follows: which constellation of measures can be recommended to best mitigate the negative effects of capacity problems in a post-COVID-19 era, depending on the capacity class of airports, future flight volume, and average aircraft size? Currently, limited airport capacity is not a serious issue due to the rapid decline in air traffic volume 
caused by the COVID-19 pandemic in 2020. However, at some point in the future air traffic will recover and capacity problems are likely to reemerge. For this analysis we employ two scenarios, named high scenario (HS) and low scenario (LS), for the year 2040, to demonstrate the potential effects of different developments in demand on the capacity needs of airports. These scenarios are characterised by two different paths to recovery.

We begin with a review of the relevant literature in Section 2. Section 3 presents the model employed for the analyses in this paper. In Section 4 we discuss the two scenarios for the year 2040, the effects of new runways and of employing bigger aircraft at constrained airports, and the preferred constellation of these options with regard to the size of airports and the aircraft they handle. We then draw a series of conclusions in Section 5.

\section{Literature Review}

Well-known long-term forecasts for global air traffic are typically conducted by aircraft manufacturers such as Airbus [1], Boeing [2], and supranational organisations such as the ICAO [3]. However, these forecasts have had to be updated because of the sharp decline in air traffic volume caused by the COVID-19 pandemic. There are different views on how air traffic might recover over the next few years or even the next decade. Gudmundsson et al. [4] forecast that a recovery in world passenger volume would most likely last until 2022 (66.5\% probability) or 2023 (27.5\% probability) and assign only a low probability to the recovery lasting until 2026. In a more recent study, Brian Pearce from IATA [5] forecasts that the traffic levels of 2019 will be reached once again between 2022 and 2023. Global industrial production and trade were already $2 \%$ above 2019 levels by February 2021. Pearce points out that different markets will recover at different speeds, and regions with large domestic markets such as Asia Pacific will recover earlier. In an updated version of their Commercial Market Outlook (CMO), Boeing [2] forecast that it would take about four to five years for air traffic to reach 2019 levels; however, they concede there is a great deal of uncertainty about this. The CEO of Fraport, Stefan Schulte [6], expects only a modest influence on the long-term development of air traffic. Finally, Airbus [7] expects the commercial aircraft market to have recovered between 2023 and 2025, i.e., it would take four to six years to reach pre-crisis levels. Eurocontrol [8] presented three scenarios for European air traffic: in the first scenario, an effective vaccine is available in 2021 and 2019 levels of air traffic are reached in 2024. In the second scenario, the vaccine is available in 2022 and the recovery will have been completed sometime in 2025. In the third scenario, there is no effective vaccine available and recovery is delayed until around 2029. From our perspective, the latter seems to be an overly pessimistic view given the latest developments. Nevertheless, because of the high degree of uncertainty on future development of the COVID-19 pandemic, these forecasts should be treated with a bit of caution.

Airlines and airports have been affected in different ways by the COVID-19 pandemic. Those that were well financed/funded and relied more on domestic markets with standard economy class fares recovered more quickly than those serving more international markets [9]. Typical measures taken by airlines to respond to the crisis were changing flight operations, rationalising the fleet, reducing staff numbers, and reconfiguring networks and capacity [10]. Airlines chose smaller and more cost-efficient aircraft to handle the reduced demand and remain economically viable [11]. Notably, the lower level of demand during the COVID-19 pandemic enhanced the on-time performance of airlines [12]. Another airline strategy is to focus more on air cargo, which has been affected much less by the crisis and is acquiring increasing importance because of online deliveries [13]. From the perspective of airports, slot reallocation at hubs, e.g., ensuring there are more available for domestic traffic, could help speed up the recovery and be a valuable strategy for supporting smaller airports, which otherwise will need larger amounts of governmental subsidiaries to survive the pandemic [14].

Various studies have been conducted on the effects of airport capacity constraints and measures for their mitigation (all pre-COVID-19) and these can offer some guidance in the long term. In 2008, about 10-20 airports operated under capacity constrained 
conditions, including New York LaGuardia, London Heathrow, Frankfurt and Paris Charles de Gaulle. Therefore, approximately $6-15 \%$ of global air traffic was handled under capacity constrained conditions [15]. Eurocontrol [16] considered capacity constraints and forecast an average annual growth between $0.5 \%$ and $2.7 \%$ for IFR flights between 2017 and 2040 . In the most likely scenario, one of regulation and growth, they forecast an average annual growth rate of $1.9 \%$ for IFR flights. Eurocontrol concluded that there is a capacity gap of 1.5 million flights in their most-likely scenario and a capacity gap of 3.7 million flights in their global growth scenario, which is characterised by strong economic development. Due to the capacity shortage, between $8 \%$ and $16 \%$ of air passenger demand, which equates to between 160 million and 360 million people, cannot be served.

Gelhausen et al. [17] expect that almost 50 million and more than 250 million passengers worldwide will not be accommodated in 2030 and 2040, respectively. This is despite mitigation measures such as increasing airport capacity and utilisation as well as increasing larger aircrafts over time to carry more passengers per flight. Gudmundsson et al. [18] and Redondi and Gudmundsson [19] conducted extensive analyses and developed an econometric model to assess the impact of airport capacity constraints on the flight network and development of secondary hubs. In their first study [18], they identified significant spillover effects, i.e., demand shifts, from London Heathrow to London Gatwick and London City, as well as to airports such as Manchester and Birmingham. In their second study [19], they identified significant spillover effects in European and intercontinental travel from London Heathrow to Munich, Paris Charles de Gaulle, Madrid, and Doha, and from Frankfurt to Munich, Amsterdam, Abu Dhabi and Ataturk. Gelhausen [20] conducted a study that applied discrete choice analysis to analyse the impact of airport capacity constraints on airport choice among travellers in the Stuttgart region of Germany. Here, similar spillover effects were identified.

Increasing aircraft size is one of the measures for mitigating airport capacity constraints. As such, a number of studies have been carried out on aircraft size development and its relation to various factors such as competition between airlines and airport capacity constraints. Based on an analysis of Official Airline Guide (OAG) data, Burghouwt et al. [21] demonstrated for the cases of London Heathrow and Gatwick that between 2004 and 2014, capacity increases were mainly accomplished by increasing frequency in long-haul markets and by raising aircraft size in short-haul markets. By contrast, Evans and Schäfer [22,23] showed in a simulation model for the US market which comprises five airlines and 22 airports, nine of which are hubs and seven multi-airport systems, covering about $80 \%$ of the scheduled available seat miles of the US market, that there is no significant shift towards larger aircrafts. However, there is an increase in average arrival delay, which may quadruple. Furthermore, they demonstrated that airlines tend to avoid airports with high delays if there are viable alternatives. Givoni and Rietveld $[24,25]$ found that airlines tend to favour increasing flight frequency instead of aircraft size in a competitive environment. This is especially true for most high-density short-haul markets, as there is a real choice in aircraft size, albeit with some exceptions in Asia. In low-density short-haul markets, larger aircrafts are not viable whereas in long-haul markets larger aircrafts are typically the first choice. If, however, there is less airline competition, airlines tend to employ larger aircraft to accommodate the airport capacity situation. These findings are supported by Pitfield et al. [26], who analysed the traffic on North Atlantic routes between 1990 and 2006 to estimate an econometric model of aircraft size. A further study of US airports was conducted by Pai [27] who identified various factors that determine aircraft size. Fukui [28] analysed whether there is significant slot-hoarding behaviour at the airports of Chicago O'Hare, Washington National, New York JFK, and LaGuardia. Through the development of an econometric model, he concluded that the US slot system needs to be modified to reduce such behaviour. The correlation between airport capacity constraint and aircraft size was also confirmed in a model-based study by Takebayashi [29]. He demonstrated that an expansion in runway capacity leads to a temporary downshifting of aircraft size and increase in aircraft frequency. Berster et al. [30] showed that increasing aircraft size 
not only affects congested airports, but uncongested as well because of a lack of available slots at destination airports. Button [31] discusses several myths about hubs and points out a number of advantages from the perspective of the consumer. He asserts that using off-peak times more intensively is possible only to a small degree, as flights are organised in banks to coordinate the inbound and outbound journeys of airlines. Dennis [32] makes a similar argument regarding shifting flights to less congested airports: deeming this simply antithetical to the demands of passengers and hub airlines.

Another potential mitigation measure is to shift air passenger demand to other modes of transport, especially high-speed rail. Jiang and Zhang [33] analysed the welfare effects of a hub-and-spoke airline and high-speed rail providers. Amongst other things, they identified a positive welfare effect of such cooperation if the airport is capacity constrained and mode substitutability is high. By contrast, Castillo-Manzano et al. [34] revealed that the substitution potential of high-speed rail services has been overestimated in the past and that high-speed rail and airlines offer more independent services than might initially appear to be the case. Thus, to a large extent, high-speed rail services generate their own demand.

While various mitigation strategies are discussed in this paper in Section 4, we focus on an empirical analysis of two mitigation measures:

- increasing airport capacity and its utilisation, which also includes shifting flights to off-peak hours to some degree, and

- increasing seat capacity per flight and load factor, resulting in an average number of passengers per flight (referred to as aircraft size).

Furthermore, we briefly present the potential offered by high-speed rail as an alternative to flying as well as the use of telecommunication technologies as a means to reduce business travel.

\section{Overview of the Model}

This section provides a brief description of the general approach, as a detailed description of the model falls beyond the scope of this paper. The model is, however, documented in detail in Gelhausen et al. [17]. The unique feature of the model is the forecast of airport capacity constraints and its integration into the passenger and flight forecast. There is currently no other model that considers worldwide airport capacity constraints.

Figure 1 illustrates the approach of the model. As a first step, the unconstrained passenger and flight forecast is established, i.e., without the effects of limited airport capacity and aircraft upgauging, triggered by airport capacity constraints. Boxes with blue edges refer to unconstrained models while boxes with red edges refer to constrained models; that is to say, they include the effects of limited airport capacity and related aircraft upgauging. Boxes with blue and red edges refer to both categories. Passenger and flight volume per airport pair are modelled by a gravity model with various explanatory variables, of which the most important are future GDP per capita, population, and airfare development. As a result of this step we obtain a so-called unconstrained passenger and flight volume forecast for each airport pair, which represents the input for the airport capacity constraints and aircraft upgauging models. The airport capacity constraints model calculates current airport capacity for each airport using data envelopment analysis (DEA) and regression models. Here, we focus on the technical runway capacity, as opposed to the so-called declared capacity (e.g., IATA Worldwide Airport Slot Guidelines [35]), which can be well below the technical runway capacity. A discrete choice model calculates the probability for airport capacity expansion if airport capacity is not sufficient to handle the forecast demand. This enables us to calculate an expected delay for a new runway, if indeed this is possible at all. Important explanatory variables for these two models are the welfare level and the number of people living around the airport, the number of aircraft movements taking place in an airport, traffic mix, and the current airport infrastructure. The aircraft upgauging model belongs to both the unconstrained and constrained models (box with blue and red edges), as upgauging depends not only on the level of airport capacity constraints 
but also on various other factors, such as passenger demand, flight distance, and so on. Like the airport capacity constraints model, it employs data envelopment analysis (DEA) and regression. Factors such as passenger volume, flight distance, the constraints situation at airports, and traffic mix play an important role. The forecast result is the average number of passengers per flight (aircraft size) for each airport pair. Combining the future airport capacity and aircraft size per airport pair with the unconstrained passenger forecast yields the constrained forecast model. The forecast results are the constrained passenger and flight volume as well as the unaccommodated passenger demand and flight volume caused by limited airport capacity.

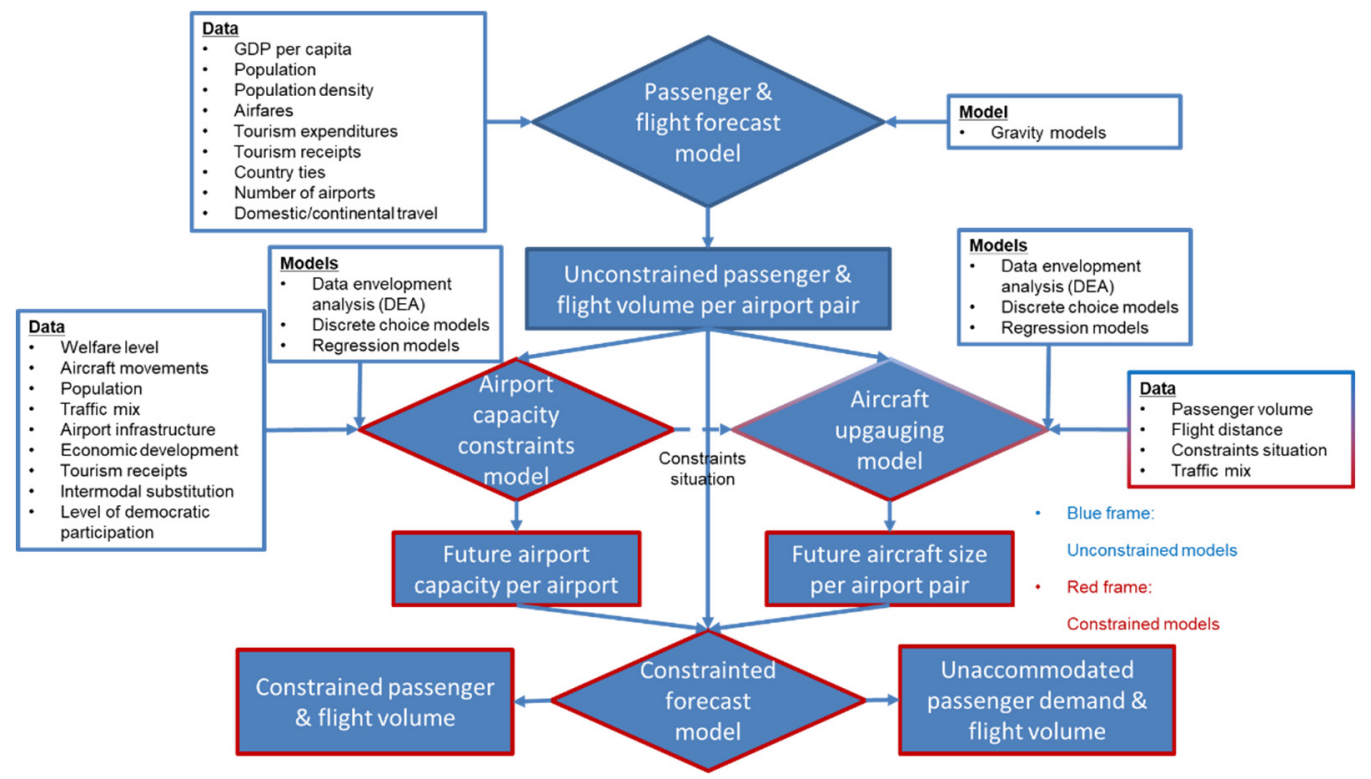

Figure 1. Overview of the forecast model (own illustration).

Figure 2 illustrates the impact of the major input factors on OD passenger demand, which underpins the forecasts. For example, if airfares rise by $1 \%$, OD passenger volume declines by $1.11 \%$. Conversely, if gross domestic product (GDP) per capita increases in the origin country by $1 \%$, then OD passenger demand rises by $0.45 \%$. Total passenger demand growth depends on the OD passenger share. If the OD passenger share is less than $32 \%$, then total passenger volume growth is higher than OD demand growth; however, if OD passenger share is higher than $32 \%$, total passenger volume growth is marginally lower than OD demand growth. GDP is broken down into four parts: GDP per capita for the origin and destination country, and population for origin and destination country. However, total GDP elasticity is 1.31 and thus OD passenger demand is elastic to GDP variations. This more or less conforms to typical results, such as those of [36,37]. However, it is important to note that we use additional variables such as distance, tourism receipts, and expenditures to account for different market segments and an airfare variable. The latter, which is generally not included in models because of a lack of suitable data on airfares in the past, typically leads to a lower modelled income elasticity because both GDP and airfares influence the purchasing power of air passengers.

The model currently contains no shift of passenger traffic to neighbouring airports if an airport reaches its capacity limit. This is clearly a limitation of the model, but it is difficult to determine a realistic share of traffic shift to neighbouring airports. In the past, increasing aircraft size has been a favoured choice in the event of capacity constraints. Figure 3 presents the example of the London area which contains the airports London Heathrow, Gatwick, Luton, and Stansted. Here, London Heathrow is a prime example of a capacity constrained airport while Gatwick, the second major airport in the London area, is heavily utilised. In fact, Gatwick is the single runway airport (it is only allowed to operate one runway) with the highest utilisation in the world, with around 280,000 aircraft 
movements in 2018. Figure 3 depicts the development of passenger volume and aircraft movements at these airports, as well as for the London area and UK between 2006 and 2019 relative to 2006. If we consider the UK or the London area as a whole, aircraft movements have remained virtually constant (UK) or increased slightly (London area $+10 \%$ ), while passenger volume has increased by 33\% between 2006 and 2019 in the UK and London area. Among the secondary airports with substantial capacity reserves, only Luton has managed to increase flight volume substantially by about $50 \%$, while there was a slight decline in Stansted between 2006 and 2019. Flight volume remained constant at Heathrow and even increased at Gatwick by about 30\%, despite the already high utilisation in 2006. Of course, past patterns might not necessarily translate into future patterns so more research on this topic is needed.

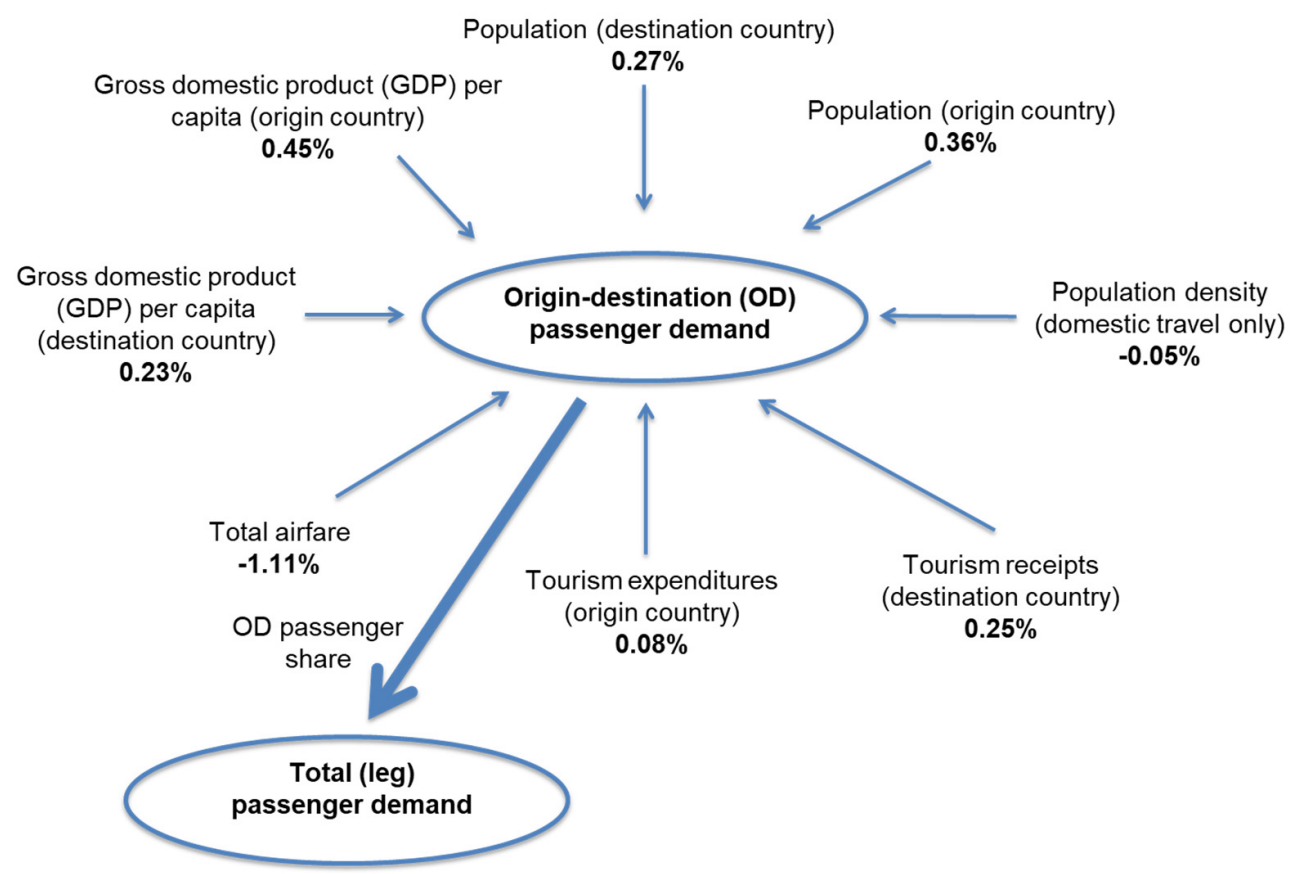

Figure 2. Major elasticities of the unconstrained passenger demand volume model [own illustration].

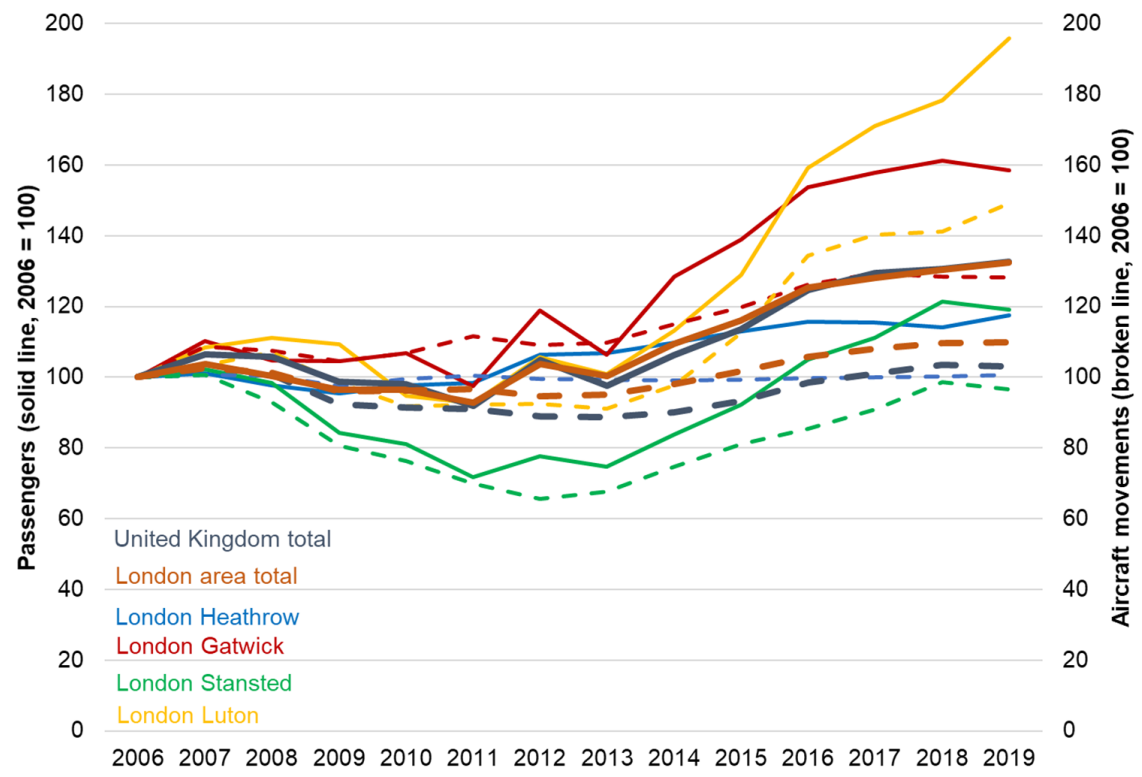

Figure 3. Relative development of passenger volume and aircraft movements at airports in the London area between 2006 and 2019 (2006 = 100) [38], [own illustration]. 
While there is currently no shift of traffic from constrained to unconstrained airports in the model, new nonstop routes are included if they become viable in terms of aircraft size, flight frequency, and load factors. However, we only consider this in terms of OD passenger demand, for instance, if a new route opens, assuming this demand can be viably served by a nonstop flight. We do not consider airline strategies actively promoting nonstop connections, which means our estimate might be a little low. However, while there has been a trend towards more nonstop flights for some time, air traffic still remains highly concentrated on a small number of airports, and this has not changed over time. Indeed, in some developing regions like the Middle East, Southwest Pacific, or Asia, concentration is still increasing - even in North America which is a highly developed region. Less than $5 \%$ of airports handle $50 \%$ of the traffic and approximately $25 \%$ of airports handle $90 \%$ of the traffic [17]. In Europe, low-cost carriers like Ryanair originally took off from secondary airports like Frankfurt Hahn (HHN) and Weeze (NRN) but now gravitate towards larger airports and even hub airports such as Frankfurt/Main. Furthermore, the traffic decline caused by the COVID-19 pandemic released attractive slots at major and hub airports, increasing the pressure on the viability of secondary and regional airports. Consequently, a more decentralised air traffic network might be farther away than ever.

In summary, shifting traffic to neighbour airports to mitigate congestion and providing nonstop rather than stopover flights are two topics which are closely interrelated. However, given past and current trends, we are less optimistic about their potential to mitigate capacity constraints on a global level, although they might be helpful at particular airports. Nevertheless, more research is needed to shed more light on these topics.

Figure 4 displays the relationship between passenger demand volume, airport capacity, and aircraft size on a very general level: to serve a particular passenger demand, we need a minimum airport capacity and average aircraft size. Both aircraft size and airport capacity limit the maximum number of passengers that can be handled. Here, aircraft size and airport capacity can substitute each other to some degree: if airport size is not sufficient to serve a given passenger demand given a particular aircraft size, increasing it can compensate for the lack of airport capacity, at least within limits, although for simplification we neglect the influence of aircraft mix on airport capacity. The same applies for airport capacity. A lack in aircraft size can be substituted by increases in airport capacity so that more flights, but with fewer passengers per aircraft on average, can be handled. However, airport capacity is typically the bottleneck, as an enlargement of airport capacity, in particular the runway system, takes a long time or is even impossible due to opposition from the nearby population, especially in highly developed countries. Popular examples of this are London Heathrow [39] and Frankfurt/Main [40].

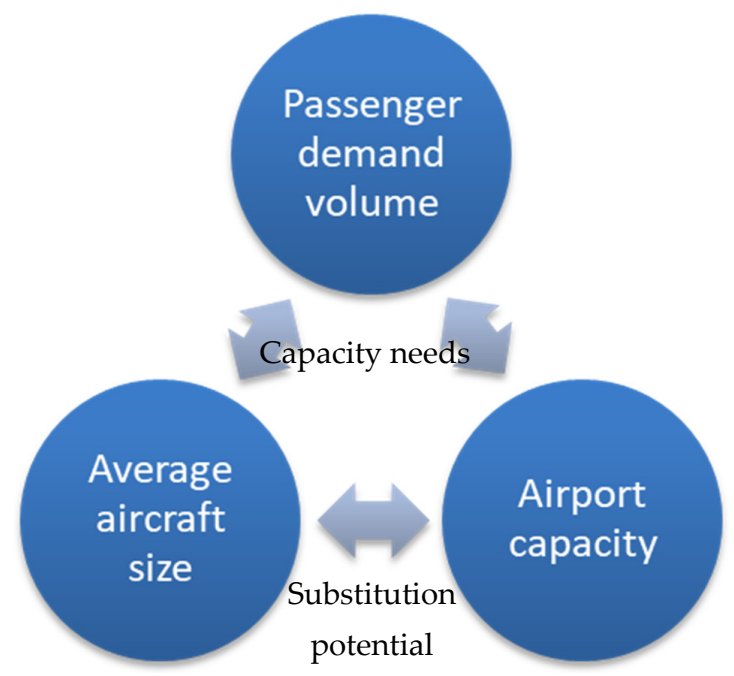

Figure 4. Relationship between passenger demand, airport capacity, and aircraft size [own illustration]. 
The bottom line is that if we account for these interrelations between passenger demand, airport capacity, and aircraft size, we will see adjustments to all three elements in a constrained forecast compared to an unconstrained forecast: there will be some degree of unaccommodated passenger demand, stronger growth of average aircraft size, and less airport capacity available in the future. An unconstrained forecast always assumes the best case regarding the development of airport capacity, which means that potential bottlenecks are neglected. However, this is not realistic, as evidenced in the example of London Heathrow.

The model generally targets the long-term development of air transport, i.e., a period of about 10 years and more. Therefore, we do not account for short- and medium-term fluctuations. Figure 5 illustrates the long-term development of global air transport in the light of a periodic major crisis, which seem to happen around every 10 years. Following previous crises, global air transport development returned to the original growth path within a few months or years; the exception being the COVID-19 crisis, which is not yet over.

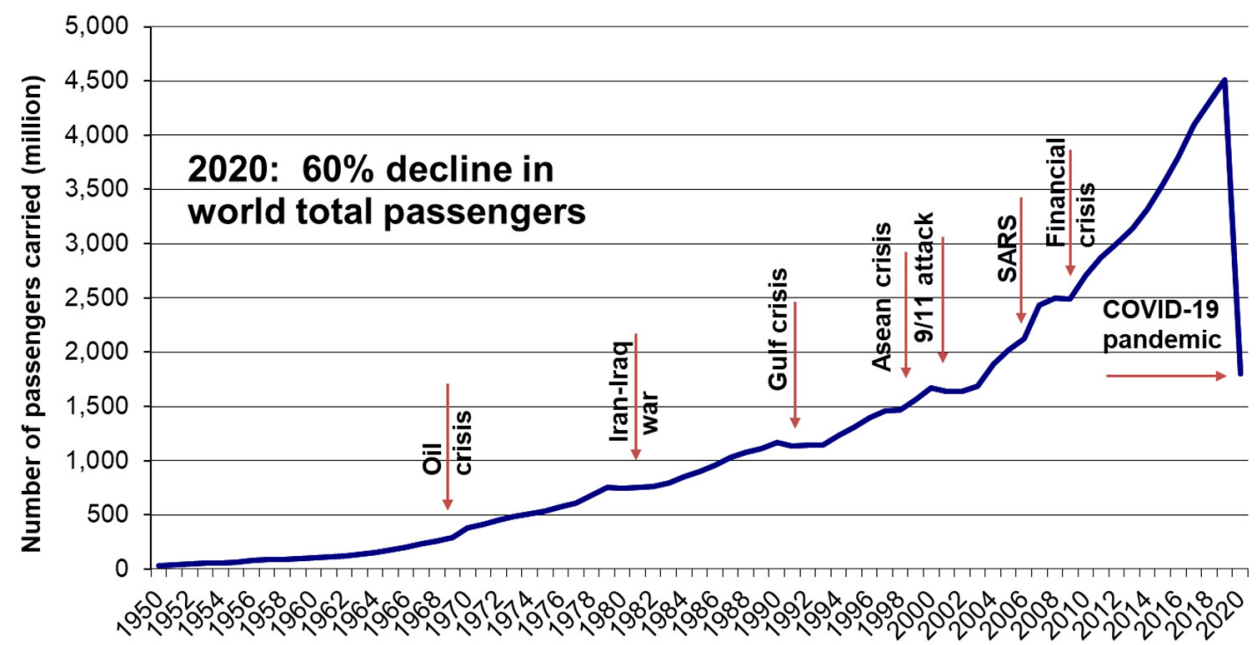

Figure 5. Development of global air traffic since 1950 [41], [own illustration].

The short-term breakdown of global air transport caused by the COVID-19 pandemic has been unprecedented in its extent compared to previous crises (see Figure 5). The magnitude and length of the downturn may lead to adaptions in passenger behaviour that outlast the COVID-19 pandemic. In particular, the increased use of telecommunication technologies may lead to a reduced demand for business trips. There are no exact numbers on actual business trips worldwide, although there are surveys covering particular markets such as Germany and the UK. Mason [42] estimates that the market for business trips constitutes approximately $30 \%$ of the total passenger market. He forecast the business trip market worldwide to be between $55 \%$ (low scenario) and $86 \%$ (high scenario) of the pre-COVID-19 forecast in 2039. The central forecast is 77\%.

Figure 6 displays the development of total seat capacity by region relative to 2019 levels. This shows that North America is close to $-20 \%$. Africa, Europe and South America are also recovering and have reached levels approximately $30-40 \%$ lower than corresponding 2019 values. The Middle East and Asia lag behind, while the Southwest Pacific has fallen to around $-60 \%$, probably due to the reoccurrence of COVID-19. In this paper, we do not present a forecast of the short- to medium-term development of global air traffic in the light of COVID-19 but take a long-term view of the year 2040 without explicitly forecasting the road taken to get there. 


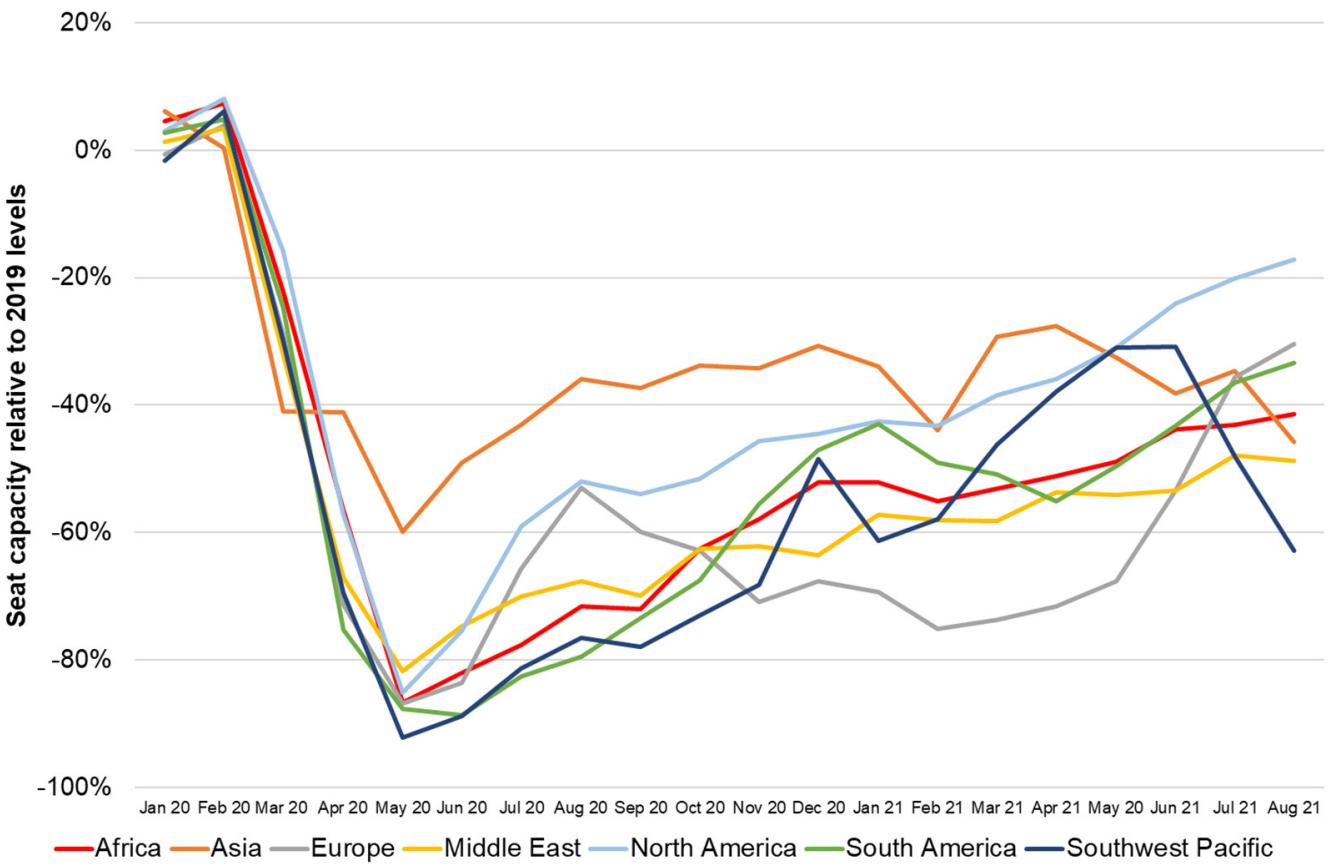

Figure 6. Development of total seat capacity by region between Jan 20 and Aug 21 relative to 2019 levels [38], [own illustration].

\section{Forecast Scenario Results and Strategic Implications}

Airport-specific recommendations regarding the enlargement of capacity can be deduced only from an analysis of the future capacity needs of that airport. However, the factor driving the employment of larger aircraft falls within the strategic planning of airlines and this measure affects the capacity needs of airports, which have limited means to interfere with and influence this process. The capacity planning of airports concentrates more on the investment option of enlarging infrastructure capacity. Given that both system partners-airlines and airports-affect the future capacity needs of airports, a case can be made for a combined airport-specific, as well as a general capacity planning strategy.

Before considering general recommendations, we first discuss the different effects of the two optional types of mitigation, aircraft size and the runway measure, on capacity gain. The capacity gained by adding new runways decreases in line with the number of existing runways, because operations on different runways interfere with each other. This is especially true in the case of dependent runway systems, while we can assume that moving from a single runway to two or maybe three independent runways, such as those at Beijing Capital City (PEK), respectively doubles or triples capacity. If we now consider the probability of realising a new runway, which might be below $100 \%$ because of opposition from the nearby population, the expected capacity gains are even lower. As a result, adding runways can be a powerful measure for mitigating congestion, especially at smaller airports. However, once a particular airport-specific threshold has been reached, it becomes less effective because of low expected marginal capacity gains.

It is important to note that there is a constant linear relationship between aircraft size and passenger capacity: if we double the number of passengers per flight, for example by increasing seat capacity per flight and/or higher load factors, we have twice the passenger capacity per flight. Thus, the throughput of a runway increases in terms of passengers carried per hour without the need to increase runway capacity. Nevertheless, changing the fleet mix at an airport affects separation minima, a factor we do not consider. Optimal sequencing of aircraft is an option to reduce separation minima and is practiced at many congested airports. Furthermore, increasing aircraft size in our model is not simply a case of adding a few very large aircraft to replace a number of very small jets, as aircraft size grows across the whole fleet, not just at the top end. Finally, there is typically a short-term and long-term maximum viable aircraft size, which cannot be exceeded in a given time frame; 
for example, due to fleet retirement plans. This also dampens the increase of separation minima, as the aircraft at the lower end catch up. For instance, some light aircraft are replaced by medium aircraft and some medium aircraft are replaced by large aircraft, but at some point large aircraft cannot grow any more. This is of course a simplified view and it is important to keep track of this to avoid overestimating the gains from increasing aircraft size.

For this paper, we defined two scenarios:

- In the low scenario (LS), we assume that by 2040, future air transport development is delayed by about five years, i.e., that pre-crisis levels of the year 2019 will be reached once again in 2024. Thus, the COVID-19 pandemic has had a permanent effect on air traffic development.

- In the high scenario (HS), we assume that the COVID-19 pandemic will be fully overcome by 2040 , i.e., air transport is once again on its original growth path, which was forecast in or before 2019. In this case, the COVID-19 effect will be levelled out in the long term.

These two scenarios were chosen based on current views reflected in the literature (see Section 2), thus the low and high scenarios cover a realistic spectrum of possible recovery developments that seem to have a higher probability of being realised, while excluding overly pessimistic views on future air traffic development scenarios that seem to be rather unlikely.

Table 1 presents the global forecast results for 2040 for the two scenarios. Despite the COVID-19 pandemic and the delay of five years in air transport development, passenger and revenue passenger kilometres (RPK) volume is forecast to increase by $84 \%$ in the low scenario until 2040 compared to 2018. The average growth rate in the low scenario between 2018 and 2040 is 2.8\% (compound annual growth rate, CAGR). In the high scenario, passenger and RPK volume increase by $114 \%$ until 2040, resulting in a CAGR of $3.5 \%$. The same growth rates for passenger and RPK volume are a result of the air transport network not changing substantially. The number of flights increases to 49.4 million in the low scenario (CAGR of $1.1 \%$ ) and 52.7 million in the high scenario (CAGR of $1.4 \%$ ), which is an increase of between $27 \%$ and $36 \%$. The number of passengers per flight rises to 164 (CAGR of $1.7 \%$ ) and 179 (CAGR of $2.1 \%$ ), respectively, indicating increasing aircraft size contributes slightly more to handling the additional passenger volume than better utilisation of existing runways and adding new runways. This is a result of the rather high utilisation of large airports and the difficult realisation of new runways or even airports. One exception is the new Beijing Daxing (PKX) airport in China, which opened in 2019 and has resulted in big capacity gain for the Beijing region. In the high scenario, there are 24 airports that cannot be enlarged sufficiently until 2040, while this number reduces to 12 in the low scenario because of the lower level of demand. These are all large hub airports such as Mumbai (BOM), New Delhi (DEL) and even Beijing Daxing (PKX) as well as Capital City (PEK) in Asia, Atlanta (ATL), Newark (EWR) and LaGuardia (LGA) in the US, and London Heathrow (LHR) in Europe. Unaccommodated passenger volume in 2040 is estimated to reach 119 million passengers in the low scenario and 256 million in the high scenario. This is the point where the COVID-19 crisis has the biggest impact. High levels of unaccommodated passenger demand are more of a long-term problem, and a setback of about five years in air traffic development has a significant effect. However, unaccommodated demand is distributed extremely unevenly among airports, such that it plays an important role for particular airports in 2040 and earlier.

We can compare our forecast results with those of Boeing [2] and IATA [43]. Currently, Airbus does not offer an updated post-COVID-19 forecast. Before the pandemic, Boeing forecast that the RPK volume would rise by $4.6 \%$ per year on average between 2019 and 2039, while they lowered their forecast to a growth rate of $4.0 \%$ after the pandemic. The Boeing forecasts are significantly higher in terms of growth rates than DLR, but the difference between pre- and post-COVID-19 is almost identical, i.e., between 0.6 and 0.7 percentage points per year. The IATA forecast has three different scenarios, with 
the "Down" scenario being similar to our low scenario and the "Up" and "Baseline" scenarios comparable to our high scenario. The IATA forecast spans a slightly broader spectrum of possible future developments compared to the DLR approach, but the results are very similar.

Table 1. Global forecast results for 2040 for the low and high scenario (compound annual growth rates in brackets).

\begin{tabular}{|c|c|c|c|}
\hline DLR & 2040 Low Scenario & 2040 High Scenario & \\
\hline Passenger volume (billion) & 8.1 ( $2.8 \%$ p.a. $)$ & 9.4 (3.5\% p.a.) & \\
\hline RPK (billion) & $14,578.2$ (2.8\% p.a.) & 16,876.1 (3.5\% p.a.) & \\
\hline $\begin{array}{l}\text { Unaccommodated } \\
\text { passenger volume (million) }\end{array}$ & 119.1 & 255.5 & \\
\hline $\begin{array}{c}\text { Total unconstrained } \\
\text { passenger volume (billion) }\end{array}$ & 8.2 & 9.7 & \\
\hline Flight volume (million) & 49.4 (1.1\% p.a.) & 52.7 (1.4\% p.a.) & \\
\hline $\begin{array}{l}\text { Passengers per flight } \\
\text { ("aircraft size") }\end{array}$ & 164 (1.7\% p.a.) & 179 (2.1\% p.a.) & \\
\hline $\begin{array}{l}\text { Number of airports that } \\
\text { remain constrained }\end{array}$ & 12 & 24 & \\
\hline Boeing & $\begin{array}{l}\text { Boeing CMO } \\
2021-2040\end{array}$ & $\begin{array}{l}\text { Boeing CMO } \\
\text { 2019-2038 }\end{array}$ & \\
\hline RPK (billion) & 19,283.1 (4.0\% p.a.) & $19,941.3$ (4.6\% p.a.) & \\
\hline IATA & IATA Down 2040 & IATA Up 2040 & IATA Baseline 2040 \\
\hline Passenger volume (billion) & 7.8 (2.6\% p.a.) & 11.7 (4.5\% p.а.) & 10.7 (4.1\% p.a.) \\
\hline
\end{tabular}

Regarding the impact of COVID-19 on business travel, we refer to the aforementioned study of Mason [42]. According to his forecast, there will be between $14 \%$ and $45 \%$ (central: 23\%) fewer business trips until 2039 compared to pre-COVID-19 forecasts. Combined with a share of business trips of approximately $30 \%$ of all air passengers, this means between $4 \%$ and $14 \%$ (central: $7 \%$ ) fewer air travellers until 2039, resulting in a reduction of passenger CAGR by about 0.2 and 0.7 percentage points (central: 0.3 percentage points). In the worst case, this can transform our high scenario into a low scenario. However, in the case of the central and high forecasts, the effects are rather limited. Nevertheless, these results should be treated with some caution: there might be a degree of double-counting in our low scenario because we have already assumed a recovery delay in the passenger air transport market by five years. However, it is not possible to break these numbers down by region or even airport pair because of a lack of global survey data. Therefore, this is only a rough estimate that cannot be integrated into the model because of a lack of geographical resolution. Consequently, we cannot compute the corresponding numbers for Table 1, but can give an estimate for the passenger volume CAGR.

Figure 7 displays the distribution of airports with respect to the number of annual aircraft movements and passengers per flight. Each point represents aircraft movements and average aircraft size data for a specific airport for the years 2018, 2040 low scenario, and 2040 high scenario. The distribution of airports indicates that the vast majority of airports are in the low range in terms of flight volume, which denotes relatively small volumes of around 200,000 movements per year over the entire range of average aircraft sizes to around 400 passengers per flight. A small number of airports will, in future years, reach volumes of up to one million movements with aircraft sizes ranging between 120 and 250 passengers per flight. 


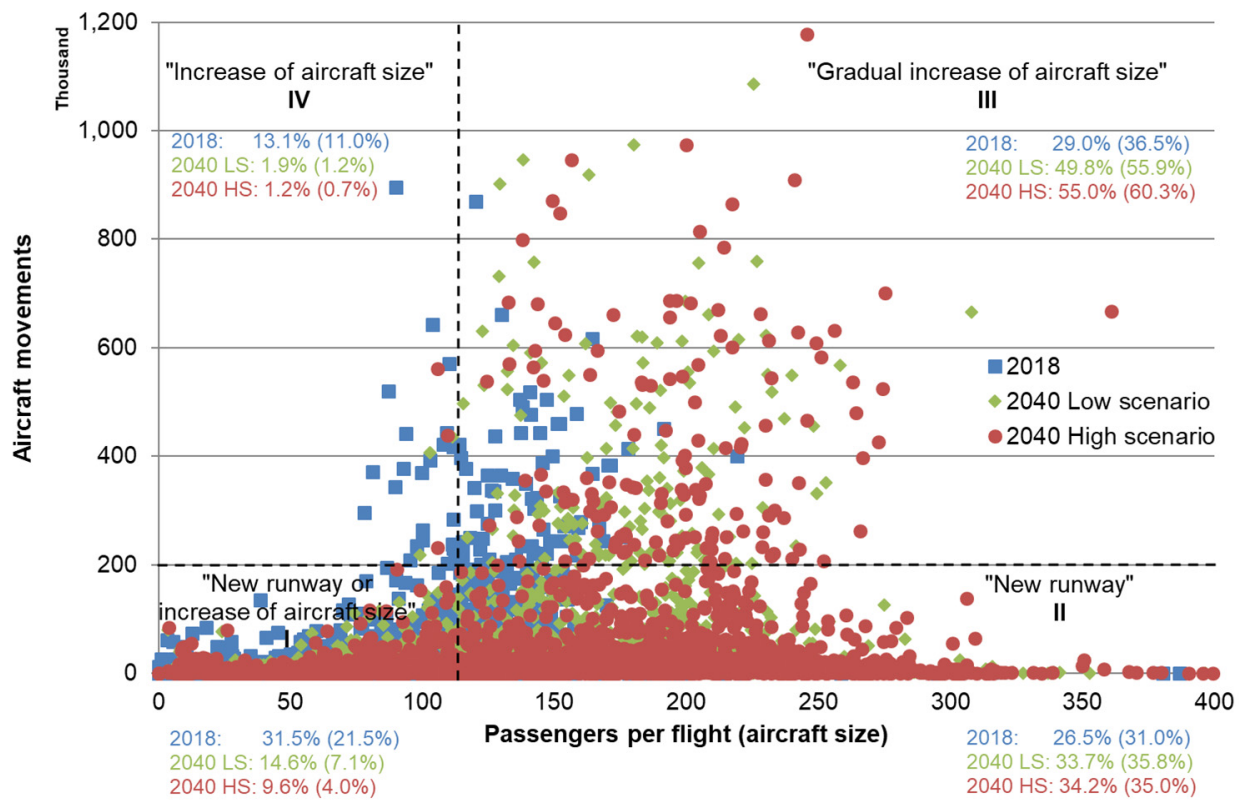

Figure 7. Global classification of airports according to mitigation strategies and their share of global aircraft movements for the years 2018, 2040 low scenario (LS), and 2040 high scenario (LS) (in brackets: airports' share of global passenger volume), 2018 data are taken from Sabre Market Intelligence [36] (own illustration and forecast).

The diagram is divided into four quadrants, separated by a horizontal line at a value of 200,000 aircraft movements and a vertical line at 114 passengers per flight. The volume dividing line was selected as the practical annual service volume of a single runway. Although the capacity of a runway may be higher, perhaps around 240,000 movements, the limit of 200,000 corresponds to a service volume that can be handled with a high level of service. The vertical line represents the average aircraft size of 114 passengers in 2018. Airports in these quadrants are characterised by certain flight volume and aircraft size ranges. Those with small flight volumes and aircraft are included in quadrant I. Airports with small traffic volumes but with higher numbers of passengers per flight are in quadrant II, while airports with greater flight volumes as well as aircraft size are located in quadrant III. Finally, airports with high volumes and rather small aircraft are in quadrant IV. General mitigation strategies vary in accordance with the volume and aircraft size of airports.

Although airports in quadrant I handled approximately $22 \%$ of global passenger demand and $32 \%$ of the flight volume in 2018 , their relative importance will decline in line with the growth of traffic in the future, even if traffic development is delayed by a few years because of the COVID-19 pandemic. Depending on the future development of air traffic, airports that remain in this category will handle only about $4 \%$ in the high scenario and $7 \%$ in the low scenario of passenger demand and $10 \%$ and $15 \%$, respectively, of the traffic. Constrained airports in quadrant I will take full advantage of both mitigation types-increasing aircraft size as well as runway capacity - provided they have the choice of realising these options.

Airports in quadrant II will grow in importance: their traffic share will rise from $27 \%$ in 2018 to $34 \%$ in both scenarios for 2040, while their passenger volume share will rise from $31 \%$ in 2018 to $35 \%$ in the high scenario and 36\% in the low scenario. These airports will primarily benefit from enlarging runway capacity. If flight operations on each runway can be managed independently, a new runway will double the capacity of single runway airports, which represent a common capacity class in quadrant II. Increasing aircraft size is therefore a secondary option, especially for those airports with average aircraft sizes in the range of 120-200 passengers per flight. 
Airports with higher traffic volumes and larger average aircraft size are more likely to be those with capacity problems. Airports in quadrant III constitute this category and require mitigation strategies more than airports in other quadrants. In 2018, airports in this category handled $29 \%$ of the traffic, which until 2040 will rise to $50 \%$ in the low scenario and $55 \%$ in the high scenario. The passenger volume share will also increase accordingly from $37 \%$ in 2018 to $56 \%$ in the low scenario and $60 \%$ in the high scenario. This group of airports will thus become the most important. In 2018, most of the airports handled aircraft ranging between 120 and 230 passengers per flight in size; hence a gradual increase in aircraft size might be the most beneficial strategy for coping with capacity shortages. However, there is one caveat: the forecast made by the model regarding aircraft size is based upon past developments and the constraints situation at airports, not the future availability or actual sales of bigger aircraft. Aircraft size in the model increases as long as it is viable and necessary in the light of limited airport capacity. Therefore, the model might overestimate the positive capacity effects of increasing aircraft size because of limited aircraft availability in the future. This means the constraints situation can be even worse and ultimately air traffic growth delayed. For airports with traffic volumes of below around 400 thousand movements per year, investment in a new runway may also be an option, especially if their average aircraft size already exceeds around 230 passengers per flight. For airports with extremely high volumes of traffic, new runways provide relatively small additional value. A better solution may be to open a new airport in the same agglomeration, as is the case in Beijing. In such cases, full capacity gain may be realised by the additional runway system.

The airports in quadrant IV handle high traffic volumes with smaller sized aircraft containing fewer than 114 passengers per flight. There are relatively few airports of this type and, as can be seen in Figure 7, their traffic share was extremely small in 2018 and will diminish in the future in both scenarios. Their first mitigation strategy should be to handle a greater number of large aircraft, thereby increasing the passenger throughput per runway without raising the flight volume. However, because airports of this type will be negligible in future, such mitigation strategies will not contribute to solving the global capacity problem.

As we have demonstrated, airports with high traffic volumes, as well as aircraft with a large number of passengers on board (in quadrant III), are the most important group (as measured by their share of the global traffic) and also the most problematic as they have the highest share of airports with a heavily utilised infrastructure and at least partly severe capacity constraints. Solutions for mitigating the capacity problem vary from airport to airport. As a general strategy, we propose a further increase in aircraft size and new runway capacity for airports with a small number of runways along with new capacity in the form of a new airport for existing airports with a complex runway system. We note, however, that these proposed strategies may be impossible to realise due to local and political constraints.

The second most important group consists of airports with traffic volumes below 200,000 annual aircraft movements and aircraft exceeding 114 passengers per flight in size (in quadrant II). The general mitigation strategy would comprise an investment in additional runway capacity and, for airports with relatively small aircraft of up to 200 passengers per flight, an increased number of flights with greater passenger capacity. However, once again, new runways may be not a feasible solution in many instances for airport-specific reasons, which means airports will have to rely on non-investment solutions such as a growth in average aircraft size.

Before we turn to more airport-specific analyses, we shed light on the distance distribution of the flights in the two scenarios. In both cases, approximately $44 \%$ of passengers fly less than $1000 \mathrm{~km}$ on a single flight, while around $17 \%$ of passengers fly less than $500 \mathrm{~km}$. However, we need to remember that passengers might take stopover flights, especially for longer journeys. If we look at particular regions, for example Asia, these values increase to around $51 \%$ for flights up to $1000 \mathrm{~km}$ and $18 \%$ for flights up to $500 \mathrm{~km}$. Other large continental markets like Europe and North America are within this range. 
In Asia, and especially in China, the state has invested heavily to promote the development of high-speed rail. Therefore, while high-speed rail theoretically offers enormous potential to mitigate the capacity crunch, it is difficult to forecast with adequate precision how much of that potential will be realised in the future. For such a task, an intermodal choice model on a global level is required, which is beyond the scope of the paper. Nevertheless, high-speed rail can offer benefits in mitigating airport capacity constraints if sufficient investments are made and passengers are willing to switch. This is especially important for the quadrant III airports in Figure 7, as enlarging airport capacity is typically difficult to realise and the potential for increasing aircraft size further is limited.

Having examined global development, we now analyse four example airports:

- Atlanta Hartsfield-Jackson (ATL) in the US with five runways.

- Frankfurt (FRA) in Germany with four runways, the fourth of which was added late in 2011.

- $\quad$ London Heathrow (LHR) in the UK with two independent runways, where we will discuss a third runway option as outlined by the Airports Commission in 2015 [39].

- The hub airports of Beijing in China, Beijing Capital City (PEK) and Beijing Daxing (PKX), which opened late in 2019. However, these two airports will be handled as one airport system in the following analyses.

Figure 8 displays the unaccommodated passenger volume at the example airports for both scenarios. This is substantial without adequate infrastructure investments: it reaches 21 million passengers for ATL in the low scenario and 34 million passengers in the high scenario, which corresponds to $11 \%$ and $15 \%$, respectively, of the unconstrained demand volume. The situation is similar at LHR: unaccommodated demand volume rises to 16 million passengers in the low scenario and 25 million passengers in the high scenario, corresponding to $11 \%$ and $15 \%$, respectively, of the unconstrained demand volume. Conversely, these values are extremely low for FRA, PEK/PKX, and LHR with a third runway, as they only suffer from indirect capacity constraints. Unaccommodated demand volume for these cases is almost negligible in both scenarios and stands at around one to two million passengers, which is approximately $1 \%$ of the unconstrained demand volume.

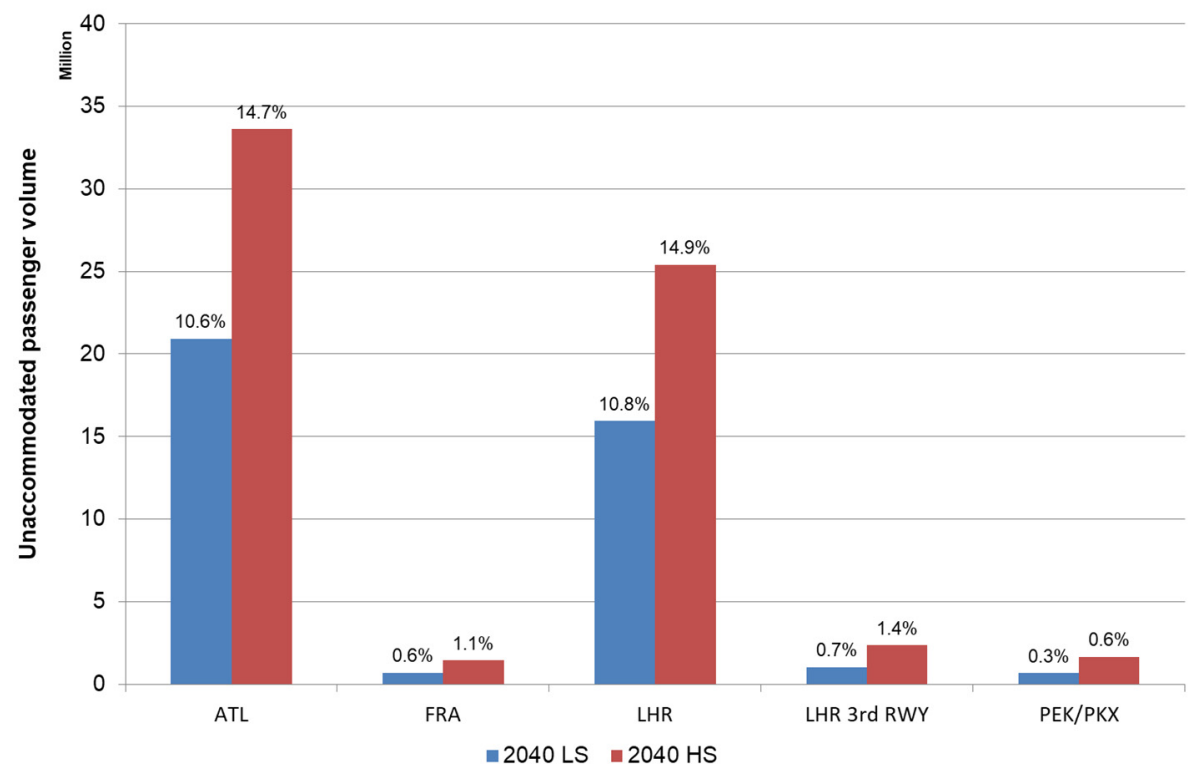

Figure 8. Unaccommodated passenger volume of the sample airports for 2030 and 2040 (values above the columns represent the share of unaccommodated passenger volume that forms part of the unconstrained passenger volume).

As Figure 8 illustrates, the forecast development is not sufficient for ATL and LHR without an additional runway. This means a large amount of passenger demand will not be served due to a lack of airport capacity. Figure 9 depicts the average aircraft size needed 
at the sample airports for both scenarios to avoid unaccommodated passenger demand. This only applies to ATL and LHR with two runways because FRA, PEK/PKX, and LHR with three runways will not experience a capacity shortage. ATL needs an additional increase in aircraft size of 22 passengers per flight in the low scenario and 35 passengers per flight in the high scenario, while LHR needs an increase of 30 and 48 passengers per flight, respectively. This results in 202 and 235 passengers per flight at ATL and as many as 281 and 324 passengers per flight at LHR for the low and high scenarios, respectively. The question then arises as to whether this is realistic, especially in the case of LHR. Based on past development and the results of the forecast model, it probably is not which underlines the importance of additional airport capacity, especially at airports such as LHR.

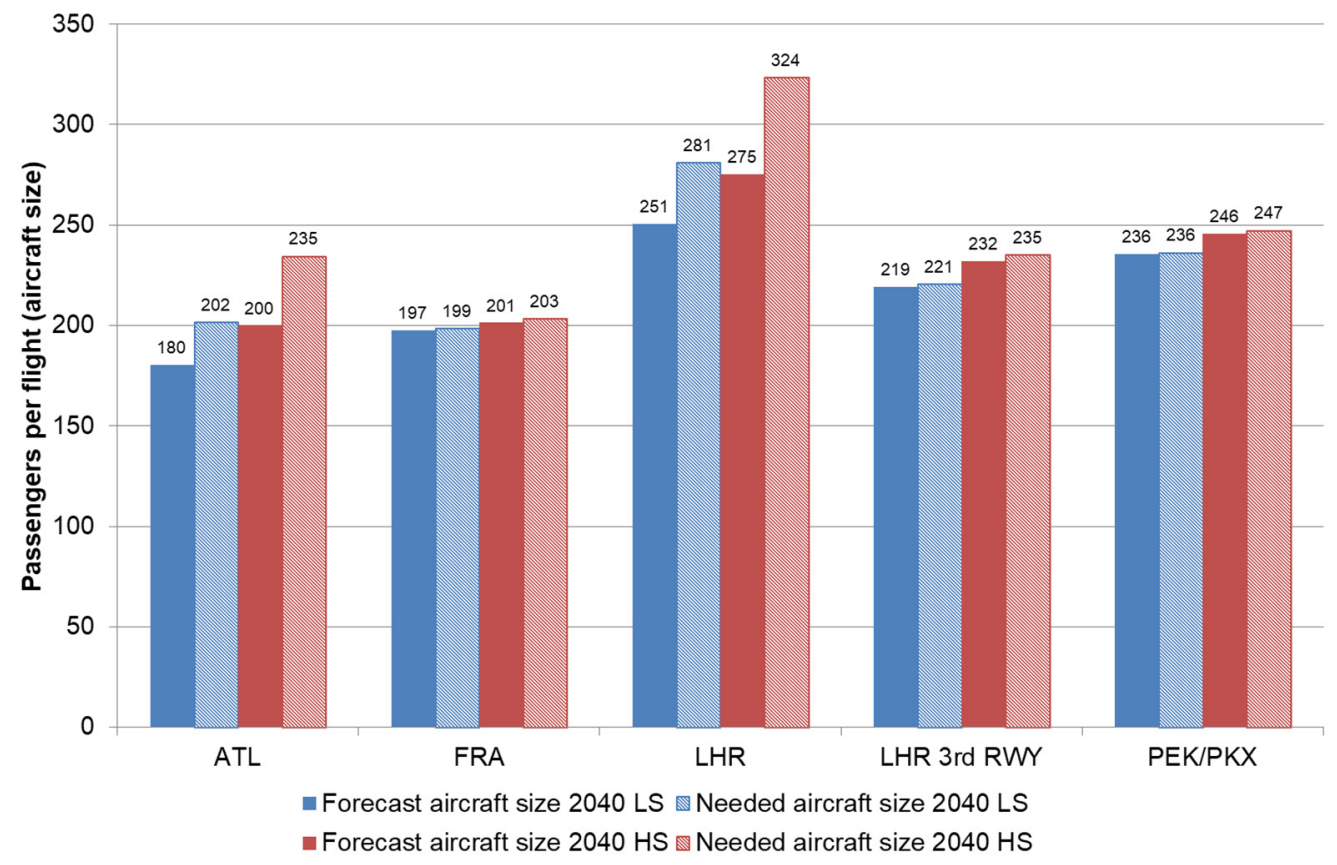

Figure 9. Forecast aircraft size and aircraft size needed to avoid unaccommodated demand for the sample airports for 2030 and 2040.

The key message from the previous analysis is that the COVID-19 pandemic has not solved the global crunch in airport capacity. While there is a notable release of pressure on airport capacity in the low scenario, as indicated by the reduction in unaccommodated demand and a less steep increase in aircraft size, both on a global level as well as at particular airports like LHR and ATL, the pressure remains at a very high level. The increase in aircraft size and unaccommodated demand are expected to be high in 2040. The situation substantially worsens in the case of the high scenario. Thus, we present ideas on how the capacity crunch and mitigation measures can be effectively managed; although additional research is clearly needed.

As we have seen, there is a need to employ even larger aircraft, i.e., with more passengers per flight, in the future to avoid the airport capacity crunch, particularly in the airports of quadrant III, which comprise several of the most important hubs of the global air traffic network. However, while airports decide on infrastructure investments and airlines schedule aircraft, both aircraft and airport capacity determine the overall number of passengers an airport can handle.

\section{Conclusions}

Our analysis indicates that most airports bearing the main burden of total traffic also have to deal with more or less severe capacity shortfalls. Among the most congested airports in 2018 were Beijing (PEK), London Heathrow (LHR), and Atlanta Hartsfield- 
Jackson (ATL). However, in 2020 there has been an unprecedented decline in global air traffic due to the COVID-19 pandemic.

Thus, the objectives of this paper were:

- to create two long-term scenarios of global passenger and flight volume given the COVID-19 crisis,

- to conduct an empirical and model-based analysis of the impact of limited airport capacity on the future development of air traffic in those two scenarios, and

- to discuss general strategies to mitigate the negative effects of airport constraints.

This involved an analysis of potential mitigation measures and the application of airport traffic forecasts until 2040 to reflect potential enlargements in capacity. According to the analysis of both scenarios, it is evident that the capacity crunch will reemerge in the long term and thus a substantial number of passengers cannot be accommodated by airports until 2040 because of insufficient capacity: in the high scenario, over 250 million passengers worldwide cannot be served while almost 120 million passengers cannot be accommodated in the low scenario. This represents between $1.5 \%$ and $2.7 \%$ of the unconstrained demand volume. Nevertheless, both scenarios suggest that we can expect an increase in passenger and flight volumes until 2040 of between $84 \%$ and $114 \%$ and $27 \%$ and $36 \%$, respectively. The large disparity between passenger and flight volume growth is a result of aircraft size increasing over time by between $1.7 \%$ and $2.1 \%$ per year on average. While the level of unaccommodated demand appears somewhat low on a global scale, the situation can be rather different at particular airports. This is especially true for global hub airports like London Heathrow which we have discussed in our case study. London Heathrow is the prime example of an airport suffering from insufficient airport capacity for a prolonged time. Between 16 and 25 million passengers will be unaccommodated until 2040 without a new runway, which represents between $10 \%$ and $15 \%$ of the unconstrained demand volume. These numbers already include a substantial increase in the number of passengers per flight, from 162 in 2019 to between 251 and 275 in 2040. To cover the lost demand, an even greater increase will be needed. Depending on the scenario, between 281 and 324 passengers per flight are necessary, which is clearly unrealistic given past trends and the results of the forecast. Adding a third runway could substantially relieve the tight capacity: virtually all of the unaccommodated demand would vanish and the number of passengers per flight can rise much more slowly. To accommodate the demand, only 221-235 passengers per flight would be needed until 2040.

Solutions for mitigating the capacity problem also vary from airport to airport. As the example of London Heathrow shows, enlarging airport capacity, especially the runway system, can be a very powerful measure for mitigating the capacity crunch if it can be realised within an acceptable time frame. Again, the example illustrates that expansion plans can fail due to opposition from the nearby population. Thus, increasing aircraft capacity is another way to create additional capacity and handle the demand for growth. There is a distinct trend toward larger aircraft worldwide. However, the driving factor for employing larger aircraft lies within the strategic planning of airlines and this affects the capacity needs of airports with only a limited means of interfering with and influencing this process.

Therefore, increasing the intermodal substitution potential through investments in high-speed rail may be an option for travelling up to $1000 \mathrm{~km}$ in the long term. It could potentially solve the capacity crunch at airports, but, as we have shown, the realisation of this depends on large investments in infrastructure and the willingness of passengers to switch from aircraft to train. It is currently extremely difficult to assess this on a global level and more research is required in this area.

We are less optimistic about the potential of telecommunication technologies in the business sector to solve the capacity problem. One caveat should be added here: a lack of appropriate surveys means it is extremely challenging to obtain detailed data on business trips on airport level worldwide in order to fully integrate this into our model. Based on a study by Mason [42], our global analysis indicates, however, that there can be reductions 
in business trips of between $14 \%$ and $45 \%$, but the potential to solve the capacity crunch is quite limited because the business segment is too small in terms of passenger numbers (not revenue). It reduces the average annual passenger volume growth rate, which is between $2.8 \%$ and $3.5 \%$, by only 0.2 to 0.7 percentage points (central: 0.3 percentage points). Nevertheless, further research in this direction would certainly be helpful in obtaining more precise and robust results. To conclude, we recommend enlarging airport capacity if it is realisable and substantial capacity gains can be achieved: for example, by adding an independent runway, which would increase annual capacity by about 200,000 to 240,000 aircraft movements. Enlarging infrastructure is dependent on the strategic planning process of airports. If capacity enlargements are not reasonable because of too little capacity gain or simply not possible because of opposition, we would focus on increasing aircraft size. However, this relies on the decision process of airlines which airports have only limited means to influence. If neither is possible or reasonable, which may especially be the case at large hub airports, an intermodal substitution like high-speed rail is an option. However, large amounts will need to be invested in infrastructure and this is entirely beyond the decision process of airports and airlines. Furthermore, there is significant uncertainty as to whether enough air passengers will be willing to switch from aircraft to train. Thus, more research and better data in this area are required.

Author Contributions: Conceptualisation, M.C.G., P.B. and D.W.; methodology, M.C.G.; software, M.C.G. and P.B.; validation, M.C.G., P.B. and D.W.; formal analysis, M.C.G., P.B. and D.W.; investigation, M.C.G., P.B. and D.W.; resources, M.C.G. and P.B.; data curation, M.C.G. and P.B.; writing-original draft preparation, M.C.G. and D.W.; writing-review and editing, M.C.G. and D.W.; visualisation, M.C.G. and P.B.; supervision, M.C.G. and D.W.; project administration, M.C.G. and D.W. All authors have read and agreed to the published version of the manuscript.

Funding: This research received no external funding.

Institutional Review Board Statement: Not applicable.

Informed Consent Statement: Not applicable.

Data Availability Statement: The data presented in this study are available on request from the corresponding author. The data are not publicly available due to commercial nature.

Conflicts of Interest: The authors declare no conflict of interest.

\section{References}

1. Airbus. Global Market Forecast 2019-2038; Airbus: Blagnac, France, 2019.

2. Boeing. Commercial Market Outlook 2021-2040; Boeing: Seattle, WA, USA, 2021.

3. International Civil Aviation Organization (ICAO). ICAO Long-Term Traffic Forecasts-Passenger and Cargo; ICAO: Montreal, QC, Canada, 2018.

4. Gudmundsson, S.; Cattaneo, M.; Redondi, R. Forecasting temporal world recovery in air transport markets in the presence of large economic shocks: The case of COVID-19. J. Air Transp. Manag. 2021, 91, 102007. [CrossRef]

5. International Air Transport Association (IATA). COVID-19-An Almost Full Recovery of Air Travel in Prospect; IATA: Montreal, QC, Canada, 2021.

6. Fraport. Fraport-Chef Schulte Sieht Luftverkehrswachstum Durch Krise nur Mäßig Gebremst. Available online: https://www. airliners.de/ fraport-chef-schulte-luftverkehrswachstum-krise-maessig-gebremst/60676 (accessed on 28 May 2021).

7. Airbus. Airbus Ramps Up Production as it Eyes Post-COVID Recovery. Available online: https://www.bbc.com/news/business57267194 (accessed on 15 June 2021).

8. Eurocontrol. Eurocontrol Forecast Update 2021-2024-European Flight Movements and Service Units-Three Scenarios for Recovery from COVID-19—Statfor, May 2021; Eurocontrol: Brussels, Belgium, 2021.

9. Warnock-Smith, D.; Graham, A.; O'Connell, J.F.; Efthymiou, M. Impact of COVID-19 on air transport passenger markets: Examining evidence from the Chinese market. J. Air Transp. Manag. 2021, 94, 102085. [CrossRef]

10. Budd, L.; Ison, S.; Adrienne, N. European airline response to the COVID-19 pandemic-Contraction, consolidation and future considerations for airline business and management. Res. Transp. Bus. Manag. 2020, 37, 100578. [CrossRef]

11. Xue, D.; Liu, Z.; Wang, B.; Yang, J. Impacts of COVID-19 on aircraft usage and fuel consumption: A case study on four Chinese international airports. J. Air Transp. Manag. 2021, 95, 102106. [CrossRef] [PubMed]

12. Yimga, J. The airline on-time performance impacts of the COVID-19 pandemic. Transp. Res. Interdiscip. Perspect. 2021, 10, 100386. [CrossRef] [PubMed] 
13. Sun, X.; Wandelt, S.; Zheng, C.; Zhang, A. COVID-19 pandemic and air transportation: Successfully navigating the paper hurricane. J. Air Transp. Manag. 2021, 94, 102062. [CrossRef] [PubMed]

14. Hou, M.; Wang, K.; Yang, H. Hub airport slot Re-allocation and subsidy policy to speed up air traffic recovery amid COVID-19 pandemic-Case on the Chinese airline market. J. Air Transp. Manag. 2021, 93, 102047. [CrossRef]

15. Gelhausen, M.C.; Berster, P.; Wilken, D. Do airport capacity constraints have a serious impact on the future development of air traffic? J. Air Transp. Manag. 2013, 28, 3-13. [CrossRef]

16. Eurocontrol. European Aviation in 2040-Challenges of Growth; Eurocontrol: Brussels, Belgium, 2018.

17. Gelhausen, M.C.; Berster, P.; Wilken, D. Airport Capacity Constraints and Strategies for Mitigation: A Global Perspective; Elsevier: New York, NY, USA, 2020; pp. 1-327.

18. Gudmundsson, S.; Paleari, S.; Redondi, R. Spillover effects of the development constraints in London Heathrow Airport. J. Transp. Geogr. 2014, 35, 64-74. [CrossRef]

19. Redondi, R.; Gudmundsson, S.V. Congestion spill effects of Heathrow and Frankfurt airports on connection traffic in European and Gulf hub airports. Transp. Res. Part A Policy Pract. 2016, 92, 287-297. [CrossRef]

20. Gelhausen, M.C. Modelling the effects of capacity constraints on air travellers' airport choice. J. Air Transp. Manag. 2011, 17, 116-119. [CrossRef]

21. Burghouwt, G.; Veldhuis, J.; Boonekamp, T.; Lieshout, R. Impacts of Expanding Airport Capacity on Competition and Connectivity-The Case of Gatwick and Heathrow; International Transport Forum; OECD: Paris, France, 2014.

22. Evans, A.; Schäfer, A. The impact of airport capacity constraints on future growth in the US air transportation system. J. Air Transp. Manag. 2011, 17, 288-295. [CrossRef]

23. Evans, A.; Schäfer, A.W. Simulating airline operational responses to airport capacity constraints. Transp. Policy 2014, $34,5-13$. [CrossRef]

24. Givoni, M.; Rietveld, P. Airline's choice of aircraft size-Explanations and implications. Transport. Res. A Pol. 2009, 43, 500-510. [CrossRef]

25. Givoni, M.; Rietveld, P. The environmental implications of airlines' choice of aircraft size. J. Air Transp. Manag. 2010, 16, 159-167. [CrossRef]

26. Pitfield, D.; Caves, R.; Quddus, M. Airline strategies for aircraft size and airline frequency with changing demand and competition: A simultaneous-equations approach for traffic on the north Atlantic. J. Air Transp. Manag. 2010, 16, 151-158. [CrossRef]

27. Pai, V. On the factors that affect airline flight frequency and aircraft size. J. Air Transp. Manag. 2010, 16, 169-177. [CrossRef]

28. Fukui, H. Do carriers abuse the slot system to inhibit airport capacity usage? Evidence from the US experience. J. Air Transp. Manag. 2012, 24, 1-6. [CrossRef]

29. Takebayashi, M. The runway capacity constraint and airlines' behavior: Choice of aircraft size and network design. Transp. Res. Part E Logist. Transp. Rev. 2011, 47, 390-400. [CrossRef]

30. Berster, P.; Gelhausen, M.C.; Wilken, D. Is increasing aircraft size common practice of airlines at congested airports? J. Air Transp. Manag. 2015, 46, 40-48. [CrossRef]

31. Button, K. Debunking some common myths about airport hubs. J. Air Transp. Manag. 2002, 8, 177-188. [CrossRef]

32. Dennis, N. Airline hub operations in Europe. J. Transp. Geogr. 1994, 2, 219-233. [CrossRef]

33. Jiang, C.; Zhang, A. Effects of high-speed rail and airline cooperation under hub airport capacity constraint. Transp. Res. Part $B$ Methodol. 2014, 60, 33-49. [CrossRef]

34. Castillo-Manzano, J.I.; Pozo-Barajas, R.; Trapero, J. Measuring the substitution effects between High Speed Rail and air transport in Spain. J. Transp. Geogr. 2015, 43, 59-65. [CrossRef]

35. International Air Transport Association (IATA). Worldwide Airport Slot Guidelines (WASG); IATA: Montreal, QC, Canada, 2020.

36. International Air Transport Association (IATA). Estimating Air Travel Demand Elasticities (Prepared by InterVISTAS Consulting Inc.); IATA: Montreal, QC, Canada, 2007.

37. Gallet, C.A.; Doucouliagos, H. The income elasticity of air travel: A meta-analysis. Ann. Tour. Res. 2014, 49, 141-155. [CrossRef]

38. Sabre AirVision Market Intelligence (MI). Data Based on Market Information Data Tapes (MIDT); Sabre: Southlake, TX, USA, 2019.

39. Airports Commission. Airports Commission: Final Report, July 2015; Airports Commission: London, UK, 2015.

40. Frankfurt Airport. Available online: https://en.wikipedia.org/wiki/Frankfurt_Airport\#The_fourth_runway (accessed on 30 August 2021).

41. International Civil Aviation Organization (ICAO). Effects of Novel Coronavirus (COVID-19) on Civil Aviation: Economic Impact Analysis; ICAO: Montreal, QC, Canada, 2021.

42. Mason, K.J. Corona Markiert Eine Zäsur bei Geschäftsreisen. Available online: https://www.airliners.de/airlinegeschaeftsmodelle-88-corona-markiert-zaesur-geschaeftsreisen/61658 (accessed on 23 August 2021).

43. International Air Transport Association (IATA). 20 Year Passenger Forecast; IATA: Montreal, QC, Canada, 2021. 